in vivo $34: 2419-2421(2020)$

doi:10.21873/invivo.12055

\title{
Extended Stability of Reconstituted Lyophilized Erwinia L-asparaginase in Vials
}

\author{
MICAELA M. VIÑA-ROMERO ${ }^{1}$, RUTH RAMOS-DIAZ ${ }^{2}$, IVETTE MOURANI-PADRON ${ }^{2}$, \\ HECTOR GONZALEZ-MENDEZ ${ }^{3}$, MACARENA GONZALEZ-CRUZ ${ }^{4}$, GLORIA JULIA NAZCO-CASARIEGO ${ }^{5}$, \\ JAVIER F. MERINO-ALONSO ${ }^{1}$, JESICA DIAZ-VERA ${ }^{2}$ and FERNANDO GUTIÉRREZ-NICOLÁS ${ }^{5}$ \\ ${ }^{1}$ Hospital Pharmacy Service, University Hospital Nuestra Señora de la Candelaria, \\ Santa Cruz de Tenerife, Tenerife, Spain; \\ ${ }^{2}$ Foundation of Health Research Institute of Canary islands (FIISC), \\ University Hospital of the Canary islands, La Laguna, Tenerife, Spain; \\ ${ }^{3}$ Hematology Service, University Hospital Nuestra Señora de la Candelaria, Santa Cruz de Tenerife, Tenerife, Spain; \\ ${ }^{4}$ Paediatric Service, University Hospital of the Canary islands, La Laguna, Tenerife, Spain; \\ ${ }^{5}$ Hospital Pharmacy Service, University Hospital of the Canary islands, La Laguna, Tenerife, Spain
}

\begin{abstract}
Background/Aim: L-Asparaginase (L-ASNase) is used as a tumor-inhibitory drug on paediatric acute lymphoblastic leukemia (ALL). ERW-ASNase is commercialised as a lyophilized powder stable only for 8 hours once reconstituted and, consequently, the leftover is usually discarded. The aim of this study will be to analyse the stability of the reconstituted lyophilised ERW-ASNase. Materials and Methods: In the present study, we analysed the enzymatic stability of reconstituted ERW-ASNase after conservation in three different temperature conditions for 2 and 5 days. Results: Our results show that ERW-ASNase is stable at $4^{\circ} \mathrm{C},-20^{\circ} \mathrm{C}$ and $-80^{\circ} \mathrm{C}$ for up to 5 days, retaining $95 \%$ of the initial enzymatic activity in all three storage temperatures tested. Conclusion: It is feasible to reuse the remaining content of ERW-ASNase vial after reconstitution, which allows the optimization of the content of ERW-ASNase vials use and reduces the cost of this formulation usage, making it more accessible.
\end{abstract}

The search for approaches that selectively target tumour cells is one of the challenges for developing drugs designed for the treatment of neoplastic disease (1). In this context, Lasparaginase (L-ASNase) has found its therapeutic niche by

This article is freely accessible online.

Correspondence to: Fernando Gutiérrez-Nicolás, University Hospital of the Canary islands, Ctra. General La Cuesta s/n, San Cristóbal de La Laguna 38320, Spain. Tel: +34 922678570, e-mail: fgunico@gmail.com

Key Words: L-Asparaginase, acute lymphoblastic leukemia, erwinia. significantly reducing the levels of asparagine in the plasma of the patients (2). Asparagine is an essential amino acid involved in the development of blast cells generated during lymphoproliferative processes, such as in acute lymphoblastic leukemia (ALL); therefore, a limitation in asparagine levels prevents the blasts from synthesizing proteins and promotes their apoptosis $(3,4)$. The mechanism of action of L-ASNase has proven to be so effective that its therapeutic use is considered one of the greatest advances in the hematology field during the last 50 years, changing the natural course of treatment for ALL patients (5). Specifically, it has allowed response rates of over $70 \%$ (6) and has increased the 5 yearssurvival rate in more than $90 \%$ of patients (7).

Currently, L-ASNase is available in three different forms: two of them produced in the microorganism Escherichia coli (E. coli) as engineered proteins, i) the first one is the native form (ASNase, L-asparaginase or Kidrolase ${ }^{\circledR}$ ) and ii) the second one is in a pegylated form (PEG-ASNase, pegaspargase or Oncaspar $\left.{ }^{\circledR}\right)$; iii) the third formulation is produced in Erwinia chrysanthemi (ERW-ASNase, asparaginase Erwinia or Erwinase ${ }^{\circledR}$ ) and its major difference compared to the E. coli counterparts is its reduced immune response (8). Therefore, ERW-ASNase is extensively used in those patients where an immune hypersensitivity to some of the forms derived from $E$. coli occurs or a silent inactivation has developed (9). ERWASNase is commercially available as a lyophilised product containing 10,000 IU per vial for its reconstitution in an injectable solution. After administration, ERW-ASNase average half-life is 16 hours (10), thus, the patient requires 2-3 weekly administrations. The recommended dose of ERW-ASNase for the paediatric population, assuming a child's surface area is between 0.7 and $1.2 \mathrm{~m}^{2}$, is $20,000 \mathrm{IU} / \mathrm{m}^{2}(8)$, however, according to the manufacturer instructions, it shows 8 hours 
stability once reconstituted (11). Reconstituted protein preservation for subsequent administrations (at 48 and $72 \mathrm{~h}$ ) is not possible, resulting in loss of economic resources. We hypothesised that reconstituted ERW-ASNase stability is in the range of days, aiming to enable the optimization of the vials content usage for consecutive administrations, thus, reducing the costs associated with the drug disposal in the treatment of ALL. The present study aimed to analyze the stability of lyophilised ERW-ASNase $\left(\right.$ Erwinase $^{\circledR}$ ) formulation under different preservation conditions.

\section{Materials and Methods}

ERW-ASNase reconstitution and stability assay. ERW-ASNase was obtained as a commercially available lyophilized powder in vials from Erwinase ${ }^{\circledR}$ (Jazz Pharmaceuticals plc, Dublin, Ireland). One single Erwinase ${ }^{\circledR}$ powder vial was reconstituted under sterile conditions following the technical data sheet guidelines. Briefly, this vial was reconstituted in $2.0 \mathrm{ml}$ of sterile distilled water to obtain a final solution concentration of approximately $5,000 \mathrm{IU} / \mathrm{ml}$, which was aliquoted into several vials. To evaluate the enzymatic activity of this ASNase preparation, each aliquot was diluted 10,000-fold in a saline solution of $\mathrm{NaCl} 0.9 \%$ in order to obtain a concentration of the drug within the linear detectable range of the assay. The activity of the stock solution at zero time point $(\mathrm{t} 0)$ was established as the reference activity (100\%). Subsequently, several aliquots of the stock solution $(5,000 \mathrm{IU} / \mathrm{ml})$ were stored in sterile Eppendorf tubes under three different conservation temperatures: i) $4^{\circ} \mathrm{C}$, ii) $-20^{\circ} \mathrm{C}$ and iii) $-80^{\circ} \mathrm{C}$. ERW-ASNase activity was measured after 2 (t2) and 5 (t5) days. Each sample was analysed in duplicate, and a third measurement was performed when the standard error was higher than $5 \%$. The enzymatic activity loss after storage was calculated as a percentage by setting the to activity as the reference value.

Asparaginase activity assay. The asparaginase enzymatic activity was measured by a spectrophotometric method using the medac Asparaginase-Aktivitäts-Test MAAT kit (medac GmbH, Wedel, Germany), a validated protocol compared to the reference method $L$-aspartic acid $\beta$-hydroxamate (AHA) (12). Each aliquot of ERWASNase stock solution $(5,000 \mathrm{IU} / \mathrm{ml})$ was diluted 10000 -fold by two consecutive dilutions: i) a first dilution $1 / 100=10 \mu$ l of stock solution $+990 \mu$ ll of saline solution and ii) a second dilution $1 / 100=10 \mu \mathrm{l}$ of previous dilution $+990 \mu \mathrm{l}$ of saline solution. According to the instructions, $20 \mu \mathrm{l}$ of the last dilution was then mixed in $180 \mu \mathrm{l}$ of the dilution buffer supplied in the MAAT kit. The resulting solutions were incubated with an asparagine analogous substrate capable of releasing a green chromatic complex upon reaction. The degradation product was determined spectrophotometrically at $690 \mathrm{~nm}$ wavelength using the Thermo Scientific $^{\mathrm{TM}}$ Multiskan ${ }^{\mathrm{TM}}$ GO spectrophotometer (Thermo Fisher Scientific Inc., Whaltham, MA, USA) and the asparagine enzymatic activity was calculated within a linear range from 30 to $600 \mathrm{IU} / \mathrm{l}$.

\section{Results}

ERW-ASNase stability after a 2-5 days storage at low temperatures. We performed a total of 14 ERW-ASNase activity measurements. All samples were measured in
Table I. ERW-ASNase activity and conservation. Direct absorbance of enzymatic activity (at $690 \mathrm{~nm}$ ) was transformed to IU/l, according to the kit specifications. Activity values were normalised to day 0 activity, and absolute values were calculated as a percentage of activity (shown in brackets). The data shown correspond to the average value of the measurements.

\begin{tabular}{lccc}
\hline & \multicolumn{3}{c}{ Activity IU/l } \\
\cline { 2 - 4 } Conservation & $\begin{array}{c}\text { Day } 0 \\
\text { t0 }\end{array}$ & $\begin{array}{c}48 \mathrm{~h} \\
\mathrm{t} 2\end{array}$ & $\begin{array}{c}120 \mathrm{~h} \\
\mathrm{t} 5\end{array}$ \\
\hline & 328 & & \\
$4^{\circ} \mathrm{C}$ & --- & $325(99.1 \%)$ & $324(98.7 \%)$ \\
$-20^{\circ} \mathrm{C}$ & --- & $303(92.4 \%)$ & $306(93.3 \%)$ \\
$-80^{\circ} \mathrm{C}$ & --- & $302(92.0 \%)$ & $320(97.6 \%)$ \\
\hline
\end{tabular}

duplicate for the reference time point ( $\mathrm{t} 0), \mathrm{t} 2$ and $\mathrm{t} 5$ time points at the storage temperature conditions of $4^{\circ} \mathrm{C},-20^{\circ} \mathrm{C}$ and $-80^{\circ} \mathrm{C}$. The reference enzymatic activity at t0 was measured as $328 \mathrm{IU} / 1$ (standard deviation lower than 5\%). The resulting ERW-ASNase enzymatic activity oscillated between 302 and $325 \mathrm{IU} / 1$, independently of the storage time and temperature (Table I). The enzyme retained over $92 \%$ of its activity in all cases, while storage at $4{ }^{\circ} \mathrm{C}$ showed the best preservation results with values over $98.7 \%$ of its original activity. In summary, the loss of ERW-ASNase activity detected was less than $8 \%$ (standard deviation lower than $5 \%$ ) in all tested storage times and conditions.

\section{Discussion}

The incorporation of L-ASNase in the treatment of patients with ALL has led to a paradigm change for this disease. Indeed, circulating asparagine elimination has allowed dramatically improving the survival of these patients (13). Currently E. chrysanthemi (Erwinase ${ }^{\circledR}$ ) is used in those patients who are intolerant to $E$. coli derived asparaginase, both the native and the pegylated form (9). Even though ALL is not a disease with a high incidence, ERW-ASNase is considered a drug with a high budgetary impact, so it is essential to propose strategies that help optimize treatment costs. In our study, we seeked to analyze the stability of the L-ASNase activity contained in the Erwinase ${ }^{\circledR}$ vials and evaluate whether this presentation would allow subsequent administrations in the time frame of the treatment, which is every 48-72 h. Our results show that the ERW-ASNase solution obtained from the reconstituted Erwinase ${ }^{\circledR}$ lyophilized powder retains more than $92 \%$ of its activity after 5 days when preserved in all three low-temperature tested conditions. The storage condition at $4^{\circ} \mathrm{C}$ was the best of all tested, probably due to the enzyme activity loss during the freeze-thaw process occurring at -20 and $-80^{\circ} \mathrm{C}$ 
temperatures. The microbiological stability was not analysed in this study, so it is important to highlight that, in case of applying this strategy for the optimization of the treatment with ERW-ASNase, it will be essential to work in aseptic conditions that ensure not only chemical stability but also the correct microbiological conservation.

In conclusion, the activity of ERW-ASNase (Erwinase ${ }^{\circledR}$ ) remains stable at $4^{\circ} \mathrm{C},-20^{\circ} \mathrm{C}$ and $-80^{\circ} \mathrm{C}$ for at least 5 days after reconstitution. This allows the vials to be used in subsequent administrations covering the whole period of the patient's treatment, with obvious saving implications in the cost of paediatric treatment of ALL.

\section{Conflicts of Interest}

The Authors declare no potential conflicts of interest concerning the research, authorship, and/or publication of this article.

\section{Authors' Contributions}

VRMM: Wrote most of the manuscript. RDR: Designed and implementation of the experimental study. IMP: Helped with experiments and provided data of table. HGM: Hematologist responsible for writing the paper's introduction. MGC: Pediatrician that contributed to introduction. GJN: Pharmacist responsible for the discussion and who chose the asparaginase activity kit. JFMA: Pharmacist responsible for section of materials and methods. DVJ: Contributed to discussion of results and editing of the paper. GNF: Director of the group and coordinator of the work and paper's writing.

\section{Acknowledgements}

This article is part of the Doctoral Thesis of Viña Romero M.M. with the Doctoral Program in Pharmacy from Granada University in Spain.

\section{References}

1 Karakunnel JJ, Bui N, Palaniappan L, Schmidt KT, Mahaffey KW, Morrison B, Figg WD and Kummar S: Reviewing the role of healthy volunteer studies in drug development. J Transl Med 16(1): 336, 2018. PMID: 30509294. DOI: 10.1186/s12967-0181710-5

2 Salzer W, Bostrom B, Messinger Y, Perissinotti AJ and Marini B: Asparaginase activity levels and monitoring in patients with acute lymphoblastic leukemia. Leuk Lymphoma 59(8): 17971806, 2018. DOI: $10.1080 / 10428194.2017 .1386305$

3 Broome JD: Evidence that l-asparaginase activity of guinea pig serum is responsable for its antilymphoma effects. Nature 191(479): 1114-1118, 1961. PMID: 14015822. DOI: 10.1084/ jem.118.1.121

4 Clavell LA, Gelber RD, Cohen HJ, Hitchcock-Bryan S, Cassady JR, Tarbell NJ, Blattner SR, Tantravahi R, Leavitt P, and Sallan SE: 4-Agent induction and intensive asparaginase therapy for treatment of childhood acute lymphoblastic-leukemia. New Engl
J Med 315(11): 657-663, 1986. PMID: 2943992. DOI: 10.1056/NEJM198609113151101

5 Silverman LB, Gelber RD, Dalton VK, Asselin BL, Barr RD, Clavell LA, Hurwitz CA, Moghrabi A, Samson Y, Schorin MA, Arkin S, Declerck L, Cohen HJ and Sallan SE: Improved outcome for children with acute lymphoblastic leukemia: Results of Dana-Farber Consortium Protocol 91-01. Blood 97(5): 12111218, 2001. PMID: 11222362 DOI: 10.1182/blood.v97.5.1211

6 Nachman JB, Sather HN, Sensel MG, Trigg ME, Cherlow JM, Lukens JN, Wolff L, Uckun FM and Gaynon PS: Augmented post-induction therapy for children with high-risk acute lymphoblastic leukemia and a slow response to initial therapy. N Engl J Med 338: 1663-1671, 1998. PMID: 9614257. DOI: 10.1056/NEJM199806043382304

7 Protocolo para Leucemia Aguda Linfoblástica de la Sociedad Española de Hematología y Oncología Pediátricas (SEHOP) en colaboración con el grupo PETHEMA. Versión LAL/SEHOPPETHEMA 2013 Versión 1.1 (21.05.13). Available at: https://www.sehh.es/images/stories/recursos/pethema/protocolos /LAL/LAL_AR_2011version-5-7-2013.pdf

8 Wang B, Relling MV, Storm MC, Woo MH, Ribeiro R, Pui CH and Hak LJ: Evaluation of immunologic crossreaction of antiasparaginase antibodies in acute lymphoblastic leukemia (ALL) and lymphoma patients. Leukemia 17(8): 1583, 2003. PMID: 12886246. DOI: 10.1038/sj.leu.2403011

9 Tong WH, Pieters R, Kaspers GJ, te Loo DM, Bierings MB, van den Bos C, Kollen WJ, Hop WC, Lanvers-Kaminsky C, Relling MV, Tissing WJ and van der Sluis IM: A prospective study on drug monitoring of PEGasparaginase and Erwinia asparaginase and asparaginase antibodies in pediatric acute lymphoblastic leukemia. Blood 123: 2026-2033, 2014. PMID: 24449211. DOI: 10.1182/blood-2013-10-534347

10 Figueiredo L, Cole PD and Drachtman RA: Asparaginase Erwinia chrysanthemi as a component of a multi-agent chemotherapeutic regimen for the treatment of patients with acute lymphoblastic leukemia who have developed hypersensitivity to E. coli-derived asparaginase. Expert Rev Hematol 9(3): 227-234, 2016. PMID: 26765930. DOI: $10.1586 / 17474086.2016 .1142370$

11 Pegaspargase (ERWINASE ${ }^{\circledR}$ ) - EPAR product information. Available at: https://www.medicines.org.uk/emc/product/ 4979/smpc

12 Lanvers-Kaminsky C, Rüffer A, Würthwein G, Gerss J, Zucchetti M, Ballerini A, Attarbaschi A, Smisek P, Nath C, Lee S, Elitzur S, Zimmermann M, Möricke A, Schrappe M, Rizzari $\mathrm{C}$ and Boos J: Therapeutic Drug Monitoring of Asparaginase Activity - Method Comparison of MAATTM and AHA Test Used in the International AIEOP-BFM ALL 2009 Trial. Therapeutic Drug Monitoring 1, 2017. PMID: 29210976. DOI: 10.1097/FTD.0000000000000472

13 Nachman JB, Sather HN, Sensel MG, Trigg ME, Cherlow JM, Lukens JN, Wolff L, Uckun FM and Gaynon PS: Augmented post-induction therapy for children with high-risk acute lymphoblastic leukemia and a slow response to initial therapy. N Engl J Med 338: 1663-1671, 1998. PMID: 9614257. DOI: 10.1056/NEJM199806043382304

Received May 30, 2020

Revised June 24, 2020

Accepted June 29, 2020 